\title{
Elements for Development of Scientific Thinking
}

\author{
Manohar Kumar Das \\ Researcher, Faculty of Education, Banaras Hindu University, Varanasi,
}

\begin{abstract}
All kinds of discovery are the consequences of the scientific thinking. Galileo Galilee, Einstein, Lavoisier, James watt, Ampere, Newton, C.B.Raman, Aryabhatta etc. all became a well known Scientist only by their scientific thinking and restless experiments. The way of thinking leading from examples to the rule or the law creation and vice-versa are the indication of scientific thinking. The human mind continues thinking always but randomly, it in this manner cannot yield any useful product. When the mind continues thinking in a definite direction, associating one fact to the next, then the mind becomes able to reach and find out the useful yield or product. Scientific thinking demands the answers for the prime questions generating from "why" and "how". Associative observation of natural elements and matter, thinking over the natural process of growth, seeking the steps of natural phenomena and processes, critical thinking over the developed scientific theories, continuity and regularity in directional thinking, seeking clarity against a doubt, open-mindedness and prejudice free, complete listening and interpretation of statements, seeking reasons of any event, seeking effects of conditions, divergent thinking at regretting situation, convergent thinking at multi-factors, reflective thinking in gap, inductive thinking in examples, deductive thinking in formula, concept of science contents, procedural activities as scientific methods are the most essential elements to compose the mind of scientific thinking. Scientific productivity of a nation depends upon the extent of the development of scientific thinking among the people of the country.
\end{abstract}

Keywords: Scientific Thinking, Convergent, Divergent, Directional thinking, and Associative observation

\section{Introduction:}

Scientific thinking is the conscious synthesis of facts to reach a meaningful term call finding. Productivity of something concrete is the result of the scientific thinking. All the scientists are the proof of the mind composed of scientific thinking. All kinds of discovery are the consequences of the scientific thinking. Production of information and communication, technology, tools, devices and machines are all examples which have all been produced by the scientific thinking. Galileo Galilee, Einstein, Lavoisier, James Watt, Ampere, Newton, C. B. Raman, Aryabhatta etc. all became a well known scientist only by their scientific thinking and restless experiments. The way of thinking leading from examples to the rule or the law creation and vice- versa are the indication of scientific thinking. There are various fields of science and technology which all deal directly with the experiment and constructivism to generate an unexpected useful product for human being and society. Calculator, computer, modem, internet and satellite are the result of deep, concentrated and logical thinking which are altogether called scientific thinking. High curiosity and consistency in the logical thought tends towards generation of a new thing and system.

Scientific thinking demands the answers for the prime questions generating from "why" and "how". Besides, it also seek the confirmation knowing 'Yes' and 'No', and associates its findings with 'Who and whose' 'What and Which', and 'When and Where'. This is free from subjectivity and personal benefits, prejudices and inertia, and always concerns with the objectivity and universality, if not so, then the utility of bulb would have been limited only upto Addison, T.V. upto J.L. Beyard, Telescope upto Galileo, Law of mass conservation upto Lavoisier, Radio upto Marcovni, the software Microsoft office upto Bill Gates, binary number system upto L. A. Lovlace and computer upto Charles Babbage themselves. Education need focus to achieve the aim of the development of scientific thinking so that the modern society may increase the human resource of science and may free the society from the bondage of superstitions, prejudices, inertia and lacks of infrastructure facilities and resources. The country India, now called developing country, can be placed in the queue of developed country by means of emphasis on development of scientific thinking in the child from the primary education to the young of the post graduation and research to enable them to be scientists for innovation and development of the nation.

\section{Elements of the development of Scientific Thinking:}

Scientific thinking within individuals can be developed by composition of the brain and the mind with the elements of scientific thinking. Following are the elements to construct scientific mind to create and invent something new for the world: 


\section{Associative Observation of Natural Elements and Matter:}

We often see and observe the natural matter composed of various elements around us, such as- air as gases; water and oils as liquids; sand, soil, salt and wood as solids but we cannot understand. Why? This inability of understanding of these matters is because of lack of an associative observation, which is the observation of a thing along with its relationship with other things around that thing and its location.

It enable one to know that nothing in this world and in the universe is independent and to know that everything is associated to one another directly or indirectly. This is the matter of understanding which is the process of scientific thinking.

\section{Thinking over the Natural Processes of Growth:}

Do you think how a plant grows into a tree? If a seed is the cause of growing plant then the next problem of understanding arises that how the seed starts coming out of the ground. Why does the seed come out of ground? There are various questions regarding human being growth, star formation, planet formation etc. These sorts of questions lead to originate scientific thinking. Longitudinal observation helps us in finding solutions of these problems.

\section{Seeking the steps of Natural Phenomena and Processes:}

How does a rainbow form? How do clouds produce thunder? How does ice rain happen? How does an earthquake happen? Why does the Earth spin on its own axis and revolve around the Sun? Scientific thinking starts developing when an individual starts thinking the steps of the natural phenomena happening in the universe. Step-by-step going forward leads to find the futuristic phenomena called foretelling, and if it's reversed then it leads to find out the origin of the phenomena. Newton tried to know the cause of falling of an apple on the ground of the earth by thinking how and why it happened so. And then, law of gravitation was constructed and formulated by Newton. Similarly, Keplar found out the law of planetary motion.

\section{Critical Thinking over the Developed Scientific Theories:}

There are a large number of scientific theories developed by the Indian and the world scientists. These theories are artificial sources to produce scientific thinking. All theories are further modifiable, but it not easy to do so, and hence, doing so will create a scientific thinking within the one doing so. Since it is evident that there is nothing perfect and perpetual in this world, but everything is tending towards perfection, not towards randomness, therefore, everything produced can be changed and something new can be produced reformulation. When we try to bring a change in a system, machine, theory or law then it needs a critical thinking to find out some faults and errors removal of which results into the formation of the new product.

\section{Continuity and regularity in Directional Thinking:}

Scientific thinking is the consequence of directional thinking in which the mind starts thinking in a definite direction. The direction of observation and thinking can be:

a) Clock wise and Anti-Clock wise

b) Vertically up-down and transversally left-right

c) Peripheral to central and vice-versa.

d) Diagonal and cross-sectional

e) Linear-circular

f) Top-bottom and vice-versa.

In each sort of thinking, there is a stop only after completion of any one of the direction mentioned. Suppose, If we start thinking from the east and tend to the west then we must continue tending toward the west until we travel to an appreciable distance, and then we need change the direction, say from the west to the north, from the west to the south, or from the west to the east, and again continue. In this way, an adequate data can be gathered for finding out something new. It needs a patience to continue, continuous-next-look, which prevents one from diverting. This process of directional thinking leads the mind to be systematic and classical. Even the unconscious mind continues the directional thinking and finds something new in the dream. For example, it was the directional thought within the scientist who had started thinking about how to construct the sewing needle, and he slept having direction thinking. Consequently, his conscious thought of the day became directional and systematic, and his mind continues thinking even in the dream of unconscious mind. The unconscious dream acted as a conscious mind and found out the way to construct a needle by looking a fish breathing-nose and eyes, and it resulted into the development of a tailoring machine with the same needle. 


\section{Seeking Clarity against a doubt:}

Scientific thinking seeks clarification. It doesn't like to conclude on the basis of insufficient data which creates a doubt in the mind. In the case of insufficiency of the data, the mind remains suspended for a decision and this state of the mind is called suspended judgment. It doesn't hurry and remains free from immediate decision. It wants to wait for the real facts.

\section{Open-Mindedness and Prejudice Free Thinking:}

A Scientist is not an enemy for any other scientist, but is a friend for one another. Nonetheless, a scientist doesn't accept all statements of other scientists. Scientists are free from any kind of prejudice, and think openly over any matter or event from the origin of their own mind. They don't worry and have no emotion about the one whose theories is falsified, because they know reality does not belong to a particular person or religion, but it is always independent and universal.

\section{Complete Listening and Interpretation of Statements:}

Individuals of scientific thinking continue thinking to have a clue to find out the solution of a problem. They often remain under the mental conflicts because of high and complex thinking. In this way, when one speaks and states some statements then the listeners respect the speaker's statements and listens completely with patience so as to receive somewhat new facts which may not have ever been produced in the mind of the listener. Later on, the matter listened is stored in the mind and paid attention to it by the listener only after observing its significance after interpretation of those statements. Scientific mind tries to reject all of the contradictory propositions.

\section{Seeking Reasons of any Event:}

The mind of scientific thinking becomes neither highly worried nor highly wonderful after any event but becomes curious to know the cause of the event. Finding of the origin is an aim of scientific thinking. The one having scientific thinking knows that nothing happens without any reason. Every event has some reasons behind the event, and the reasons can be brought out by the path called scientific thinking and activities. Gautam Buddha had also stated the same, cause and strategy, in his philosophy.

\section{Seeking Effects of Conditions:}

Scientific thinking is a process of chaining and branching of the waves of the thought producing in the mind. Everything has its beginning and ending. One action is associated with other actions. Environment has several matters and facts but these facts are of no use until these are associated together. Scientific mind tries to re-arrange all of these available data and facts in the environment in a proper order and sequence. One object is situated on its place according to some conditions, and that is affected by some other conditions in some ways. This is scientific thinking that tries to know that what will happen if some of the present conditions will be changed and re-ordered.

\section{Logical Operation of Statements:}

Scientific thinking utilizes propositions. It runs according to the inductive and deductive process of thinking. It cares and remains always conscious to whether the statement is universal, partially positive, partially negative or fully negative. The use of 'all', 'some are', 'some are not', and 'not any' are all consciously done by the man having scientific thinking which runs through logical operations.

\section{Divergent Thinking at Regretting Situation:}

In the way of synthesis to reach the solution of a problem, the mind of scientific thinking runs the waves of thought, and gets diverted in different directions frequently. In this way, the insight rises by imagining various objects, and a new way of synthesis in the mind starts to understand the situation. Thus, the divergent thinking brings multi-factor images in the mind, some of which may be helpful in the way of finding a solution at the time of regretting situation, dilemma and conflicts.

\section{Convergent Thinking at Multi-Factors:}

Convergent thinking is the process of centralization of thought upon a particular matter. When the mind is not controlled then it continues bringing images involuntarily. In this kind of process of thinking, the mind tries to associate all the outside existing facts into one common fact. Thus, this sort of scientific thinking enables one to know how many objects and facts are associated together. It unites several facts and creates a new system or product. 


\section{Reflective Thinking in Gap:}

Reflective thinking can be understood by the process of reflection of light. When a ray of light falls upon the surface of an object then the ray of the light does not get absorbed onto the surface but it gets reflected from the surface of the object, and goes somewhere else from the object. Similarly, the waves of thought in the mind after falling upon any object goes away from the object and enable the mind to imagine something else. Thus, reflective thinking is the scientific process of mind to see the relationship of an object with others which helps us in creativity and constructing something.

\section{Inductive Thinking in Examples:}

There are various processes taking place in the world and the universe. All processes are following some conditions and rules. If some of the rules or the conditions are changed, the stability will get disturbed, and an unexpected event may take place, that's, some of fruitful situations may be destructive. If we try to find out a common rule or point on the basis of which something is running or happening then this process is called inductive process of thinking. It is the process of finding out the origin, law or formula from various examples and facts. The scientist Becon was its founder. It is composed of original synthesis of thought. Various formulae have been formulated and various discoveries have been done in science subjects by this process.

\section{Deductive Thinking in Formula:}

In deductive thinking, we try to solve different problems on the basis of the already made formulae, rules and laws. Already made formulae are the artificial means of scientific thinking. There are various laws and formulae established and formulated by different scientists in the scientific world. When we apply the formulae in the field of application, and exemplify them then this is deductive thinking. This is a kind of traditional mode of producing scientific thinking. It demands within the individuals an ability of micro-analysis of the preexisting rules and laws. Implication of the formulae in various fields of life requires conceptual understanding of the laws and the rules after the formulae which radiate a ray to give a path or direction for thinking.

\section{Concept of Science Contents:}

Concept of the contents of science subject is the primary condition for those who want to develop a better and more innovative theories, laws and formulae than those already developed. Concept of science depends upon the self-study of science books, science related articles, discoveries and journals.

There is no use of the science teaching methods if the concept of science contents is not dominant in the mind. This is because the concept of science can generate a spontaneous ability within individuals to experiment, demonstrate, explain and illustrate the science contents before any one, whereas the knowledge of teaching methods of science cannot generate the concept of science contents, since the training focuses on "How to teach" which is only for learning of teaching methods, as in B.Ed. training in India, rather than on "What to teach" which is for direct conceptualization of contents.

The greater is the time expended in the study of science contents, the better is the concept of science and the higher is the extent of scientific thinking. Scientific thinking and productivity, and utility of science directly depend on the concept of science within the individual.

\section{Procedural Activities as Scientific Methods:}

There are various scientific methods described by various scientists for finding the solution of a problem, but there is subjectivity in those and a lack of objectivity and universality. Hence, the best scientific method is that which is independent of any person. For examples, J.B. Chitambaram (1977) in the "Introductory Rural Sociology", A.B. Shah (1964) in the "Scientific Method", W.L. Borg and M.D. Gall (1983) in the "Educational research: an Introduction", Anderson, Alfred, Dyrly, Kellogg, Kochendorfer and Meigand (1970) in the "Developing Children Thinking Through Science" and T. Hillway (1964) in the "Introduction to Research" have all mentioned scientific methods somewhat different in steps to find out the solution of a problem. However, most of them are close to the following steps of the scientific method to develop scientific thinking to find out solution of a problem:

I Identification and Statement of the Problem

II Hypotheses Formulation

III Research Design and Experiment

IV Data collection and analysis

V Testing of Hypotheses

VI Conclusion and Reporting of Findings

In actual practice, method depends on the type of the problem. It depends on what method you apply and how you solve a problem. The methods already developed are not the exact steps but are approximate and helpful. However, these develop a better scientific thinking, and later on, the scientific thinking developed will 
itself searches out another new scientific method. There can be various methods to solve the same problem. The best scientific method is that by which you can solve a problem in a systematic way and that which is followed by some others to solve their problems.

\section{Conclusion:}

- For developing the scientific thinking, it is essential for an individual first to know what elements and components compose the scientific thinking.

- Scientific Thinking is the mental activity which results into behavior and product.

- Understanding of how natural growth happens, how some natural phenomena occur, what causes a particular event, and what affects a particular object and human being lead an individual to develop a better scientific thinking.

- Assimilation of already developed and scientifically proved processes and modes of thinking, like inductive-deductive thinking, convergent-divergent thinking, Critical thinking, and reflective-directional thinking directly enhances scientific thinking.

- Some traits of human being, like- open-mindedness, interest in science and observation, curiosity of inquiry and finding solution, continuity and consistency in directional thinking develop scientific thinking.

- Self-study, listening of others with patience, acceptance by logical operation, concept in science contents, and knowledge about scientists and scientific methods develop scientific thinking in individuals.

\section{References:}

[1]. Anderson, Alfred, Dyrly, Kellogg, Kochendorfer \& Meigand (1970). "Developing Children Thinking Through Science", Prentice Hall Inc, New Jersey, P-5.

[2]. Borg, W.L. \& Gall, M.D. (1983). "Educational research: an Introduction”, $4^{\text {th }}$ Edition, Longman, New York, PP.24-26.

[3]. Chitambaram, J.B. (1977). "Introductory Rural Sociology", Wiley Eastern Ltd., New Delhi, $2^{\text {nd }}$ Reprint, PP. $37-38$.

[4]. Dewey, John (1933). "How We Think", D.C. Heath \& Company, P-12.

[5]. Hillway, T. (1964). "Introduction to Research", $2^{\text {nd }}$ Edition, Highter Mifflin Company, Boston.

[6]. Keeslar, Oreaon (1945). "A survey of Research Studies Dealing with the Elements of Scientific Methods as Objective of Introduction in Science", Science education, vol-29, PP.212-216.

[7]. Pearson, Karl (1911). "The Grammar of Science", $3^{\text {rd }}$ Edition, Black London, Part-1, PP.6 \& 12.

[8]. Shah, A.B. (1964). "Scientific Method", Allied Publishers Pvt. Ltd., Bombay, PP-53. 